\title{
TO THE HELP OF EAST PAKISTAN CYCLONE VICTIMS
}

Last month, we published an article on the vast relief action undertaken by the League of Red Cross Societies and numerous National Societies for the victims of the cyclone and tidal wave which devastated the Bengal region, the East Pakistan coastal area and its off-shore islands in November 1970. This action has assumed large proportions, and the League has published various items of information regarding the relief despatched. Supplies delivered by 59 donor National Societies to the end of December 1970 were estimated at approximately 43 million Swiss francs.

We mentioned in our previous number that the European Economic Community had drawn from its stocks for Nigeria a certain quantity of foodstuffs which the ICRC had made available to the League for its relief operations in Pakistan. Most unfortunately, a plane carrying part of this relief food crashed. This was announced by the League and the ICRC on 3 December.

A turboprop plane, chartered in Luxemburg by the International Committee of the Red Cross to fly relief food to cycloneravaged East Pakistan, crashed and disintegrated while approaching to land at Dacca airport, on 30 November. All four crew members were killed instantly. They were:

Captain Omar Tomasson (born 1934), Reykjavik; Co-pilot Birgir Oern Jonsson (born 1940), Reykjavik; Flight-Engineer Stefan Olafsson (born 1938), Reykjavik; Flight-Mechanic JeanPaul Tompers (born 1938), Luxemburg. 


\section{IN THE RED CROSS WORLD}

The President of Pakistan, General A. M. Yahya Khan, cabled the following message of sympathy:

"I am deeply shocked and grieved to hear about tragic crash of a C-144 cargo plane near Savar carrying relief materials from the Red Cross for the cyclone victims of East Pakistan, and the death of all its crew members. The accident is all the more tragic and poignant as it took place only a few miles from Dacca, when the plane was coming in to land. The crew members, who were on a mercy mission to relieve human misery and suffering, have given their lives in a noble cause. I express our deepest sympathies and grief on behalf of the people of Pakistan at this unfortunate accident. Please convey my sincere condolences and the condolences of my Government and the people of Pakistan to the members of the bereaved families."

From Dacca, Mr. Justice B. A. Siddiky, Chairman of the Pakistan Red Cross, also sent a message of sympathy:

"Deeply distressed tragic accidental plane crash which took lives of four crew men on Red Cross mission of aid to our country. Kindly transmit most sincere and heartfelt condolences to bereaved families and charter company:"

The Foreign Affairs Minister and Home Secretary of Pakistan also sent messages of sympathy.

\section{Germany}

\section{Federal Republic}

It is very important for National Societies to make known to a wide public in their countries, through the medium of the press, radio, television or publications of their own, those important legal provisions which lay down the principles underlying 